\title{
The calculated stability of DNA duplexes containing an oxidized guanine lesion pairing with guanine
}

\author{
Masayo Suzuki, Katsuhito Kino ", Masayuki Morikawa, Taihei Watanabe, Eriko Asada, \\ Takanobu Kobayashi and Hiroshi Miyazawa
}

Kagawa School of Pharmaceutical Sciences, Tokushima Bunri University, 1314-1, Shido, Sanuki, Kagawa 769-2193, Japan

Tel.: +81-87-894-5111; Fax: +81-87-894-0181.

E.Mails: s120002@stu.bunri-u.ac.jp (M.S.), s110702@stu.bunri-u.ac.jp (M.M.), s098103@stu. bunri-u.ac.jp (T.W.), s098001@stu.bunri-u.ac.jp (E.A.), kobayashit@kph.bunri-u.ac.jp (T.K.), miyazawah@kph.bunri-u.ac.jp (H.M.)

*Author to whom correspondence shold be addressed; E-Mail: kkino@kph.bunri-u.ac.jp

\begin{abstract}
DNA is damaged by various oxidative stresses. Oxidized DNA can increase mutations and the risk of cancer. Guanine is highly sensitive to several oxidative stresses due to its low oxidation potential. It is known that 2,2,4-triamino-5 $(2 H)$-oxazolone $(\mathrm{Oz})$, iminoallantoin (Ia) and spiroiminodihydantoin ( $\mathrm{Sp}$ ) are oxidized guanine lesions. These oxidized bases can be paired with guanine and cause G:C-C:G transversions.

Although our previous results showed more effective incorporation of guanine opposite $\mathrm{Oz}$ compared to that opposite Ia or Sp (K. Kino et al., ChemBioChem, 2009), G:Oz base pair was less stable than G:Ia or G:Sp base pair by ab initio calculation (M. Suzuki et al., Molecules, 2012). G:Oz forms two hydrogen bonds and is planar, while G:Ia and G:Sp have three hydrogen bonds and are nonplanar. We focus on the difference in the bulkiness of these lesions. Since DNA duplex containing a bulky damaged base tends to deviates from natural DNA duplex, we investigate whether DNA containing G:Oz as the non-bulky lesion is similar to natural DNA and more stable than that containing G:Ia or G:Sp as the bulky lesion.

We calculated the destabilization energies of the common parts except G:Oz, G:Ia or G:Sp. As a result, the structure of DNA duplex containing G:Oz was the most stable and more similar to the natural DNA. Since the DNA structure containing G:Oz has a little effect on bypass efficiency, our calculated results can account for the previous results that translesion synthesis across $\mathrm{Oz}$ was more effective than that across Ia or Sp.
\end{abstract}

Keywords: oxidized guanine lesion, bulky, G:C-C:G transversion 


\section{Introduction}

Various oxidative stresses-induced alterations in genomic information have been involved in carcinogenesis, aging, and other diseases. Since guanine has the lowest oxidation potential among the four bases, guanine is highly sensitive to several oxidative stresses. G:C-T:A and G:C-C:G transversions are observed in vivo; for instance, G:C-T:A and G:C-C:G transversions are detected with high frequency in codons 12 and 13 of the $K$-ras gene [1].

It is known that 8-oxo-7,8-dihydroguanine (8-oxoG) is a major oxidation product of guanine under various oxidative conditions (Figure 1). Since 8-oxoG can be paired with adenine but not guanine, 8-oxoG:A base pairs cause G:C-T:A transversions [2]; that is, it is assumed that $\mathrm{G}: \mathrm{C}-\mathrm{C}: \mathrm{G}$ transversions are cause by the other oxidation products of guanine.

2,5-Diamino-4H-imidazol-4-one (Iz), an oxidation product of guanine and 8-oxoG [3], is hydrolyzed to 2,2,4-triamino-5(2H)-oxazolone $(\mathrm{Oz})$ under physiological conditions (Figure 1) [3]. In our previous researches, incorporations of guanine opposite Oz were common in DNA polymerase $\alpha, \beta, \gamma, \varepsilon, \eta$, I and IV [4,5]. We previously predicted that the G:Oz base pair is planar and has two hydrogen bonds (Figure 2) [4].<smiles>Nc1nc2c(ncn2Cc2ccccc2)c(=O)[nH]1</smiles>

guanine

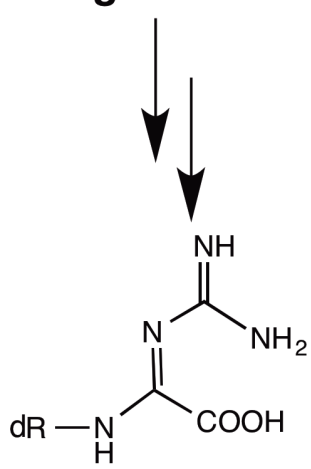

$\mathrm{Oz}$<smiles>CCCCCCCCCCCC</smiles>

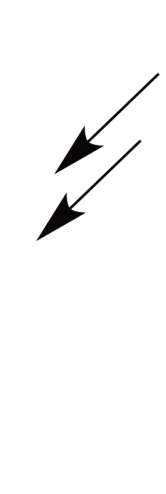

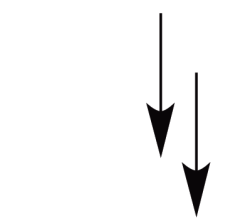<smiles>CCCN1C(=O)NC(=O)C1NC(=N)N</smiles>

Gh<smiles>CCN1C(=O)NC(=O)C12NC(N)=NC2=O</smiles>

Sp

Figure 1. Oxidative products of guanine and 8-oxoG.

Guanidinohydantoin (Gh) and spiroiminodihydantoin $(\mathrm{Sp})$ can be formed from the oxidation of $80 x o G$ (Figure 1). Gh is a major product under acidic conditions, and Sp is a representative product under basic conditions [6-9]. Although Gh is known to isomerize to iminoallantoin (Ia), 
it remains unclear which of these two isomers is predominant in DNA polymerization [10]. In our previous calculated data, G:Ia was more stable than G:Gh [11]. Thus, since we predict that Gh tautomerize to Ia when incorporation of guanine opposite Gh/Ia, we consider only Ia in the present study. In our previous study, incorporation of guanine opposite $\mathrm{Oz}$ is more effective than that opposite $\mathrm{Gh} / \mathrm{Ia}$ and $\mathrm{Sp}$, and translesion synthesis past $\mathrm{Oz}$ is more efficiently as well as incorporation efficiency [4,12]. By contrast, our calculated results showed that G:Oz was less stable than G:Ia and G:Sp owing to the difference in the number of hydrogen bonds (Figure 2) [11]. In order to resolve the contradiction between experimental results and calculated results, we focus on the difference in the bulkiness of these lesions: Oz has no $s p^{3}$ carbon and is planar, and then G:Oz are less bulky than G:Ia and G:Sp (Figure 2). Thus, since DNA duplex containing a bulky damaged base tends to deviates from natural DNA duplex, we investigate the structural similarity to natural DNA and the stability in DNA duplex containing G:Oz, G:Ia or G:Sp by calculating the energies of common parts except each base pair.

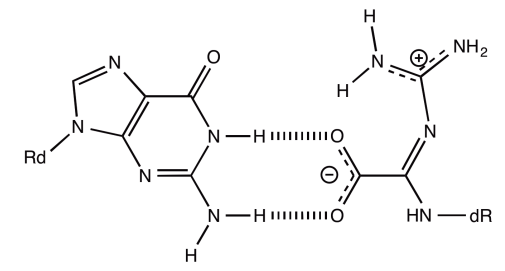

$\mathrm{G}: \mathrm{Oz}$

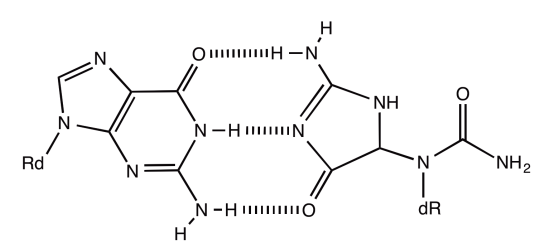

G:Ia

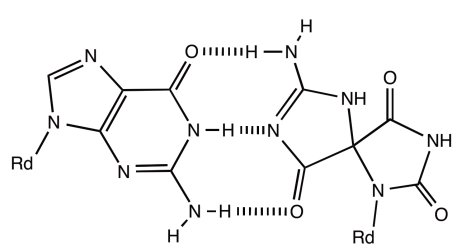

G:Sp

Figure 2. The proposed G:Oz, G:Ia and G:Sp base pairs.

\section{Methods}

\section{Molecular modelling}

In this study, we constructed the DNA polymerase $\beta$ (Pol $\beta$ ) -DNA complexes containing a $\mathrm{G}: \mathrm{X}(\mathrm{X}=\mathrm{C}, \mathrm{Oz}, S$-Ia, $R$-Ia, $S$-Sp or $R$-Sp) base pair by the modification of the structure (PDBID:1BPY). The details of the construction method were presented in below. In all models, the incoming nucleotide (dCTP) was replaced with dATP, and the template $\mathrm{G}$ of incoming nucleotide was replaced with T. Complexes of Pol $\beta$ with G:X base pair were built by replacing the G:C base pair at the 3 ' terminus of the template-primer with $\mathrm{G}: \mathrm{X}$ base pair optimized previously [11], respectively. The protein residues and other DNA base sequences remain unchanged. The geometries were minimized at the OPLS2005/water level using Macromodel 9.0 (SCHRÖDINGER) with the fixed G:X base pair. 


\section{Ab initio calculation}

All atoms were removed except for the bases of G:X base pair, those of both adjacent base pairs to $\mathrm{G}: \mathrm{X}$ base pair, the 2-deoxyribose $\mathrm{C} 1$ ' carbons and $\mathrm{C} 1$ ' $\mathrm{H}$ from the minimized structures. Two $\mathrm{H}$ atoms were then attached to the $\mathrm{Cl}$ ' methine, respectively, to complete the $\mathrm{N}$-methylated nucleobases (Figure 2). A:T base pair on the 5'-side of $\mathrm{X}$ was referred to as " $\mathrm{A}_{1} \mathrm{~T}_{1}$ ", and G:X base pair was referred to as " $\mathrm{G}_{2} \mathrm{X}_{2}$ ". G:C base pair on the 3'-side of $\mathrm{X}$ was referred to as " $\mathrm{G}_{3} \mathrm{C}_{3}$ " (Figure 3,4).

The destabilization energies $\left(\Delta E_{l}\right)$ of " $\mathrm{A}_{1} \mathrm{~T}_{1}$ " of $\mathrm{G}$ :X complexes in vacuo were calculated at the B3LYP/6-31G** level using Gaussian 03 (Gaussian Inc., Wallingford, CT, USA) [13]. Moreover, to estimate the energies in water, the SCRF values of these base pairs were calculated using the Onsanger reaction field model and a dielectric constant of 78.39. The destabilization energies $\left(\Delta E_{1+3}\right)$ of " $\mathrm{A}_{1} \mathrm{~T}_{1}+\mathrm{G}_{3} \mathrm{C}_{3}$ ", the both adjacent base pairs to $\mathrm{G}$ :X base pair, were calculated in vacuo and in water, in addition to the calculation of $\Delta E_{l}$. The calculated heat of formation of the base pairs is defined in eq. $(1,2)$ :

$$
\begin{gathered}
\Delta E_{l}=\mid E\left(\text { (" } \mathrm{A}_{1} \mathrm{~T}_{1} \text { ” of } \mathrm{G}: \mathrm{X} \text { complex }(\mathrm{X}=\mathrm{C})\right)-E\left(“ \mathrm{~A}_{1} \mathrm{~T}_{1} \text { ” of } \mathrm{G}: \mathrm{X} \text { complex }\right) \mid \\
\Delta E_{1+3}=\mid E\left(“ \mathrm{~A}_{1} \mathrm{~T}_{1}+\mathrm{G}_{3} \mathrm{C}_{3} \text { ” of } \mathrm{G}: \mathrm{X} \text { complex }(\mathrm{X}=\mathrm{C})\right)-E\left(“ \mathrm{~A}_{1} \mathrm{~T}_{1}+\mathrm{G}_{3} \mathrm{C}_{3} \text { ” of } \mathrm{G}: \mathrm{X} \text { complex }\right) \mid
\end{gathered}
$$
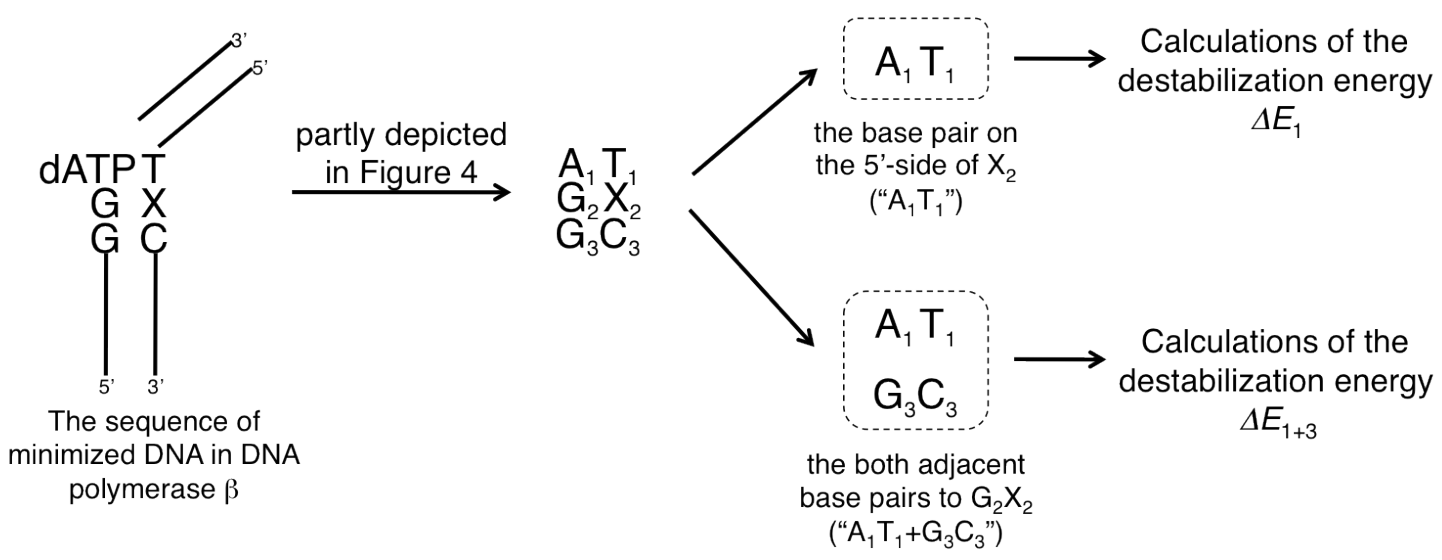

Figure 3. The outlines of the method. Each DNA polymerase $\beta$ (Pol $\beta$ ) -DNA complexe containing an G:X (X $=\mathrm{C}, \mathrm{Oz}, \mathrm{a}, R$-Ia, $S$-Sp or $R$-Sp) base pair was minimized. G:X and the both adjacent base pairs to $\mathrm{G}: \mathrm{X}$ were depicted in Figure 4. " $\mathrm{A}_{1} \mathrm{~T}_{1}$ " was A:T base pair on the 5'-side of $X$, " $\mathrm{G}_{2} \mathrm{X}_{2}$ " was $\mathrm{G}: \mathrm{X}$ base pair, and " $\mathrm{G}_{3} \mathrm{C}_{3}$ " was $\mathrm{G}$ :C base pair on the 3'-side of $\mathrm{X}$. The destabilization energies of " $\mathrm{A}_{1} \mathrm{~T}_{1}$ " $\left(\Delta E_{1}\right)$ and " $\mathrm{A}_{1} \mathrm{~T}_{1}+\mathrm{G}_{3} \mathrm{C}_{3}$ " $\left(\Delta E_{l+3}\right)$ were calculated as the common parts except the each $\mathrm{G}_{2} \mathrm{X}_{2}$. 
(a)

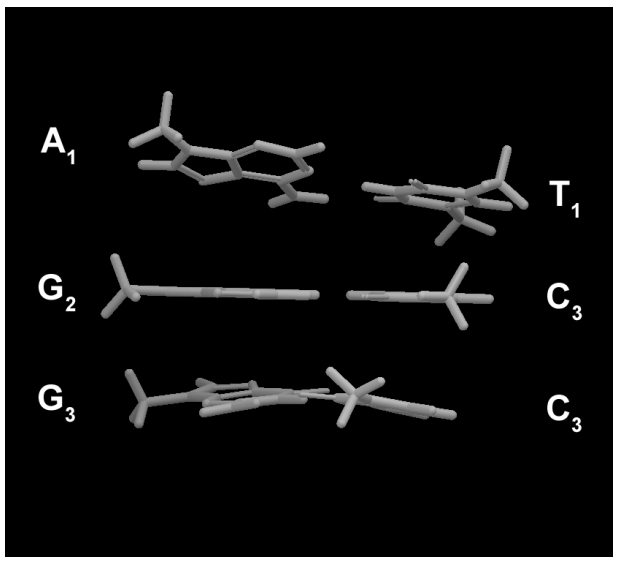

$\mathrm{G}_{2} \mathrm{C}_{2}$

(c)

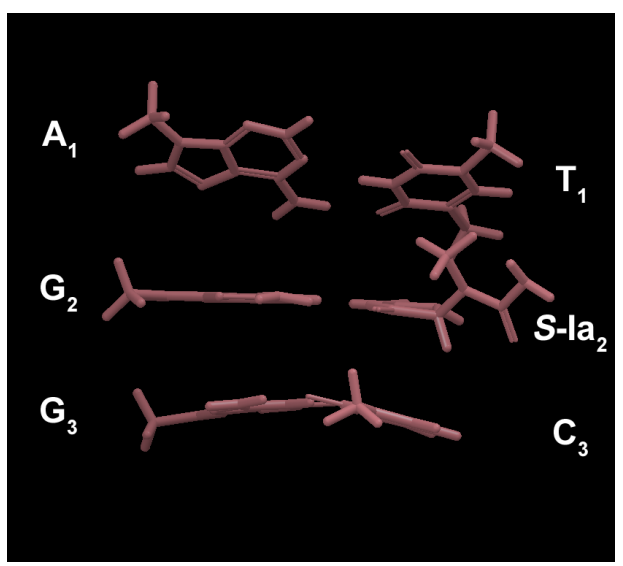

$\mathrm{G}_{2} \mathrm{~S}-\mathrm{Ia}_{2}$

(e)

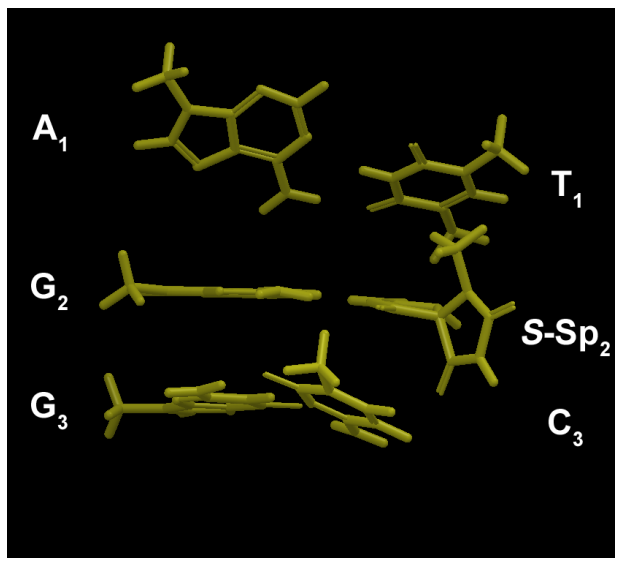

$\mathrm{G}_{2} S-\mathrm{Sp}_{2}$ (b)

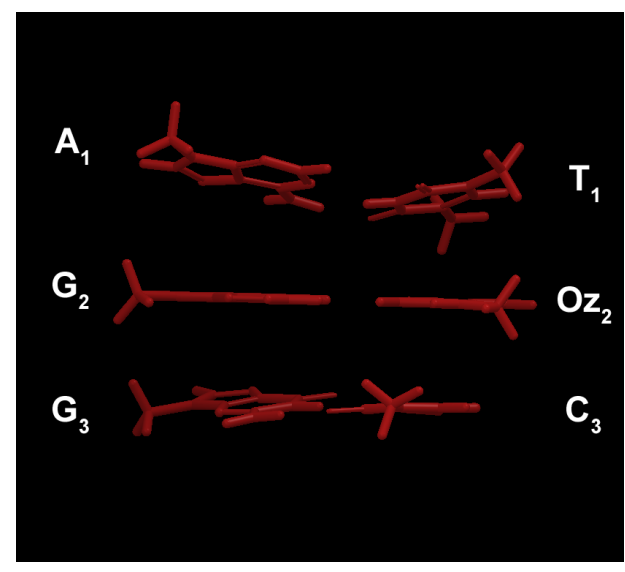

$\mathrm{G}_{2} \mathrm{Oz}_{2}$

(d)

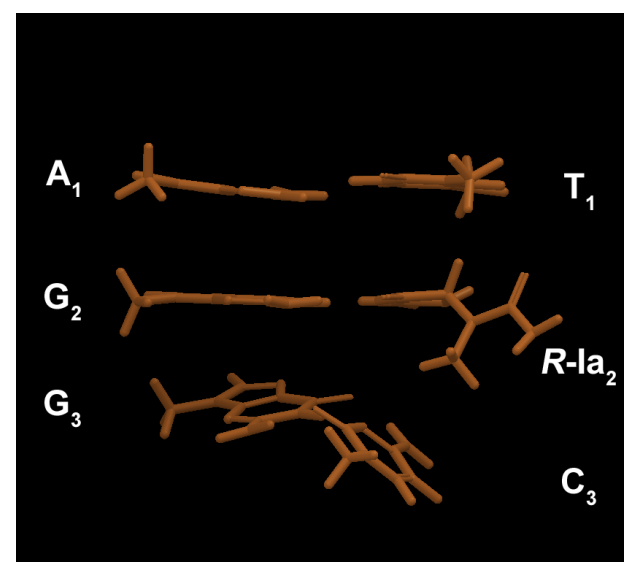

$\mathrm{G}_{2} R-\mathrm{Ia}_{2}$

(f)

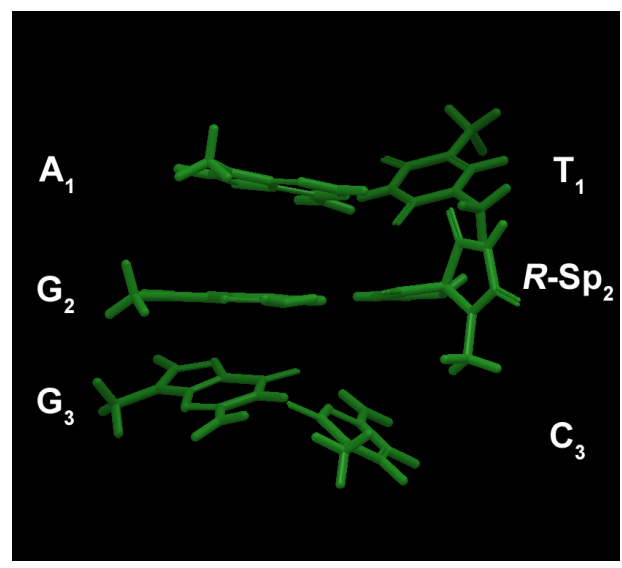

$\mathrm{G}_{2} R-\mathrm{Sp}_{2}$

Figure 4. The minimized geometries of " $\mathrm{A}_{1} \mathrm{~T}_{1}, \mathrm{G}_{2} \mathrm{X}_{2}, \mathrm{G}_{3} \mathrm{C}_{3}$ " containing $\mathrm{X}_{2}=(\mathbf{a}) \mathrm{C},(\mathbf{b}) \mathrm{Oz}$, (c) $S$-Ia, (d) $R$-Ia, (e) $S$-Sp or (f) $R$-Sp in side view from minor groove. 


\section{Results and Discussion}

Our previous study showed that the calculated stabilization energy of G:X base pair is in the following order: G:S-Ia $>\mathrm{G}: R$-Ia $>$ G:R-Sp $>$ G:S-Sp >> G:Oz. In this study, the DNA polymerase $\beta$ (Pol $\beta$ ) -DNA complexes containing an $\mathrm{G}: \mathrm{X}$ (X = C, Oz, $S$-Ia, $R$-Ia, $S$-Sp or $R$-Sp) base pair were built by modification of the structure in PDB. These geometries were minimized, and then we focused on G:X base pair and both adjacent base pairs to G:X base pair in minimized DNA (Figure 4). The minimized structure containing $\mathrm{G}_{2} \mathrm{Oz}_{2}$ (Figure $4 \mathrm{~b}$ ) seemed to resemble that containing natural $\mathrm{G}_{2} \mathrm{C}_{2}$ (Figure $4 \mathrm{a}$ ). Therefore, we evaluated the destabilization caused by the oxidized guanine lesion by calculating the energies of common parts except each base pair " $\mathrm{G}_{2} \mathrm{X}_{2}$ ".

As the energies of common parts except the G:Oz, G:Ia or G:Sp base pair, we used the destabilization energies of " $\mathrm{A}_{1} \mathrm{~T}_{1}$ " $\left(\Delta E_{l}\right)$ base pair on the 5 '-side of $\mathrm{X}_{2} . \Delta E_{l}$ of Oz, $S$-Ia, $R$-Ia, $S$-Sp and $R$-Sp were defined as eq.1 and were calculated (Table 1). The calculated $\Delta E_{l}$ of the most stable base pair, $\Delta E_{l}$ of $R$-Ia, was $0.50 \mathrm{kcal} / \mathrm{mol}$ in vacuo. $\Delta E_{l}$ of $\mathrm{Oz}$ was $1.26 \mathrm{kcal} / \mathrm{mol}$, and it was the second most. $\Delta E_{l}$ of $S-S p(2.13 \mathrm{kcal} / \mathrm{mol})$ was more stable than $\Delta E_{l}$ of $R$-Sp $(12.55 \mathrm{kcal} / \mathrm{mol})$. In water, $\Delta E_{l}$ derived DNA duplex containing $\mathrm{G}: \mathrm{X}$ was in the following order: $R$-Ia $>\mathrm{Oz}>S$-Ia $>S$-Sp $>R$-Sp, as well as in vacuo. The calculated stabilization energies in water differed by $\sim 0.19 \mathrm{kcal} / \mathrm{mol}$ of those in vacuo.

Table 1. The destabilization energies $(\mathrm{kcal} / \mathrm{mol})$ of " $\mathrm{A}_{1} \mathrm{~T}_{1}$ " $\left(\Delta E_{l}\right)$ and " $\mathrm{A}_{1} \mathrm{~T}_{1}+\mathrm{G}_{3} \mathrm{C}_{3}$ " $\left(\Delta E_{1+3}\right)$, obtained from the minimized geometries.

\begin{tabular}{|c|c|c|c|c|}
\hline \multirow[b]{2}{*}{$\mathrm{X}^{a}$} & \multicolumn{2}{|c|}{$\mathrm{A}_{1} \mathrm{~T}_{1}$} & \multicolumn{2}{|c|}{$\mathrm{A}_{1} \mathrm{~T}_{1}+\mathrm{G}_{3} \mathrm{C}_{3}$} \\
\hline & $\Delta E_{l}^{\mathrm{DFT}, b}$ & $\Delta E_{l}^{\mathrm{SCRF}, b}$ & $\Delta E_{I+3}{ }^{\text {DFT }, b}$ & $\Delta E_{1+3}^{\mathrm{SCRF}, b}$ \\
\hline $\mathrm{Oz}$ & 1.26 & 1.07 & 1.13 & 1.00 \\
\hline$S$-Ia & 1.38 & 1.26 & 4.08 & 4.46 \\
\hline$R$-Ia & 0.50 & 0.56 & 4.77 & 4.58 \\
\hline$S$-Sp & 2.13 & 2.07 & 4.83 & 5.27 \\
\hline$R-\mathrm{Sp}$ & 12.55 & 12.36 & 18.26 & 18.26 \\
\hline
\end{tabular}

Kornyushyna et al. revealed that incorporation of guanine and the extension past $\mathrm{Gh} / \mathrm{Ia}$ are more efficient than that past $\mathrm{Sp}$ [12]. Therefore, our calculated results, $\Delta E_{1}$ of $S$-Ia and $R$-Ia were more stable than $\Delta E_{l}$ of $S$-Sp and $R$-Sp, corresponded with the published results. However, 
$\Delta E_{l}$ of $\mathrm{Oz}$ was less stable than $\Delta E_{l}$ of $R$-Ia in our calculated data, which can not explain the previous experimental results that translesion synthesis past $\mathrm{Oz}$ is more efficient than that past Ia [4]. That is, it is necessary to consider the stability of the both adjacent base pairs " $\mathrm{A}_{1} \mathrm{~T}_{1}+\mathrm{G}_{3} \mathrm{C}_{3}$ " to $\mathrm{G}: \mathrm{X}$ rather than the stability of " $\mathrm{A}_{1} \mathrm{~T}_{1}$ " base pair on the 5 '-side of $\mathrm{X}_{2}$, as a way to assess the stability of the DNA duplex containing oxidation products.

The destabilization energies $\left(\Delta E_{1+3}\right)$ of the both adjacent base pairs " $\mathrm{A}_{1} \mathrm{~T}_{1}+\mathrm{G}_{3} \mathrm{C}_{3}$ " to $\mathrm{G}_{2} \mathrm{X}_{2}$, " $\mathrm{A}_{1} \mathrm{~T}_{1}$ " base pair on the 5 '-side of $\mathrm{X}_{2}$ and " $\mathrm{G}_{3} \mathrm{C}_{3}$ " base pair on the 3 '-side of $\mathrm{X}$, were defined as eq.2 and were calculated individually (Table 1). Our calculated data surprisingly showed that $\Delta E_{1+3}$ of $\mathrm{Oz}$ was $1.13 \mathrm{kcal} / \mathrm{mol}$ in vacuo, and it was the smallest among all damages. That is, " $\mathrm{A}_{1} \mathrm{~T}_{1}+\mathrm{G}_{3} \mathrm{C}_{3}$ " derived DNA duplex containing $\mathrm{G}: \mathrm{Oz}$ was the most stable. $\Delta E_{1+3}$ of $S$-Ia (4.08 $\mathrm{kcal} / \mathrm{mol}$ ) was more stable than $\Delta E_{1+3}$ of $R$-Ia $(4.77 \mathrm{kcal} / \mathrm{mol})$ in vacuo. In $\Delta E_{l+3}$ of $\mathrm{Sp}, S$ configuration $(4.83 \mathrm{kcal} / \mathrm{mol})$ was more stable than $R$ configuration $(18.26 \mathrm{kcal} / \mathrm{mol})$. In water, $\Delta E_{1+3}$ derived DNA duplex containing G:X was in the following order: $\mathrm{Oz}>S$-Ia $>R$-Ia $>S$-Sp $>R$-Sp. In other words, there is no difference in the order of the stability in vacuo and in water, which were common to both $\Delta E_{l}$ and $\Delta E_{I+3}$.

In a previous report, the stalling of polymerases is accounted for by serious disruption of crucial polymerase-DNA interaction caused by bulky lesion [14]. In the present study, $\Delta E_{1+3}$ of Oz was the most stable, which showed that DNA duplex containing G:Oz is more similar to the natural DNA. That is, our calculated data can account for the previous experimental results that translesion synthesis across $\mathrm{Oz}$ was more effective than Ia or Sp [4,12]. Moreover, in order to evaluate the stability of the DNA duplex containing G:Oz, G:Ia or G:Sp, calculating the energies of " $\mathrm{A}_{1} \mathrm{~T}_{1}$ " on the 5 '-side of $\mathrm{X}_{2}$ was not enough, but it was sufficient to calculate the energies of the both adjacent base pairs " $\mathrm{A}_{1} \mathrm{~T}_{1}+\mathrm{G}_{3} \mathrm{C}_{3}$ " to " $\mathrm{G}_{2} \mathrm{X}_{2}$ ". We will add a discussion about the effect of the bulkiness of $\mathrm{Oz}$, Ia and $\mathrm{Sp}$ on " $\mathrm{A}_{1} \mathrm{~T}_{1}$ " and " $\mathrm{A}_{1} \mathrm{~T}_{1}+\mathrm{G}_{3} \mathrm{C}_{3}$ " derived DNA duplex containing G:X base pair by parameterizing the distortion of DNA in the future.

\section{Conclusions}

In order to evaluate the destabilization caused by DNA containing G:Oz, G:Ia or G:Sp, we calculated the energies of " $\mathrm{A}_{1} \mathrm{~T}_{1}$ " $\left(\Delta E_{l}\right)$ on the 5 '-side of $\mathrm{X}$ as the common parts of DNA duplex including each G:X base pair. As a result, $\Delta E_{l}$ of $S$-Ia and $R$-Ia were more stable than $\Delta E_{l}$ of $S$-Sp and $R$-Sp in both in vacuo and in water, which corresponded to the previous experimental results that incorporation of guanine and the extension past $\mathrm{Gh} / \mathrm{Ia}$ are more efficient than that past $\mathrm{Sp}$ [12]. However, in our calculated data, $\Delta E_{l}$ of $\mathrm{Oz}$ was less stable than $\Delta E_{l}$ of $R$-Ia: Our 
data could not account for the previous experimental results that translesion synthesis past $\mathrm{Oz}$ is more efficient than that past Ia [4]. Thus, we calculated the energies $\left(\Delta E_{1+3}\right)$ of the both adjacent base pairs " $\mathrm{A}_{1} \mathrm{~T}_{1}+\mathrm{G}_{3} \mathrm{C}_{3}$ " to $\mathrm{G}$ :X. As a result, $\Delta E_{1+3}$ of $\mathrm{Oz}$ was the most stable, which showed that DNA duplex containing G:Oz is more similar to the natural DNA. That is, this structural similarity to natural DNA is the reason why translesion synthesis across $\mathrm{Oz}$ is more efficiently than that across Ia or Sp.

\section{Anknowledgements}

This work was supported by K. Kino's research grants from Japan Society for the Promotion of Science (JSPS), from Tokushima Bunri University, Japan Prize Foundation, from Radiation Effects Association. M. Suzuki and M. Morikawa were supported by a Research Fellowship from JSPS for Young Scientists.

\section{References}

1. Maehira, F.; Miyagi, I.; Asato, T.; Eguchi, Y.; Takei, H.; Nakatsuki, K.; Fukuoka, M.; Zaha, F. Alterations of protein kinase C, 8-hydroxydeoxyguanosine, and K-ras oncogene in rat lungs exposed to passive smoking. Clin. Chim. Acta. 1999, 289, 133-144.

2. Shibutani, S.; Takeshita, M.; Grollman, A.P. Insertion of specific bases during DNA synthesis past the oxidation-damaged base 8-oxodG. Nature 1991, 349, 431-434.

3. Cadet, J.; Berger, M.; Buchko, G.W.; Joshi, P.C.; Raoul, S.; Ravanat, J.-L. 2,2-Diamino-4-[(3,5-di- $O$-acetyl-2-deoxy- $\beta$-D-erythro-pentofuranosyl)amino]-5-(2H)-oxa zolone: a novel and predominant radical oxidation product of 3',5'-di-O-acetyl-2'-deoxyguanosine. J. Am. Chem. Soc. 1994, 116, 7403-7404.

4. $\quad$ Kino, K.; Sugasawa, K.; Mizuno, T.; Bando, T.; Sugiyama, H.; Akita, M.; Miyazawa, H.; Hanaoka, F. Eukaryotic DNA polymerases $\alpha, \beta$ and $\varepsilon$ incorporate guanine opposite 2,2,4-triamino-5(2H)-oxazolone. ChemBioChem 2009, 10, 2613-2616.

5. Duarte, V.; Gasparutto, D.; Jaquinod, M.; Cadet, J. In vitro DNA synthesis opposite oxazolone and repair of this DNA damage using modified oligonucleotides. Nucleic Acids Rec. 2000, 28, 1555-1563.

6. Luo, W.; Muller, J.G.; Rachlin, E.M.; Burrows, C.J. Characterization of spiroiminodihydantoin as a product of one-electron oxidation of 8-oxo-7,8-dihydroguanosine. Org. Lett. 2000, 2, 613-616. 
7. Kino, K.; Morikawa, M.; Kobayashi, T.; Komori, R.; Sei, Y.; Miyazawa, H. The oxidation of 8-oxo-7,8-dihydroguanine by iodine. Bioorg. Med.Chem. Lett. 2010, 20, 3818-3820.

8. Munk, B.H.; Burrows, C.J.; Schlegel H.B. An exploration of mechanisms for the transformation of 8-oxoguanine to guanidinohydantoin and spiroiminodihydantoin by density functional theory. J. Am. Chem. Soc. 2008, 130, 5245-5256.

9. Ye, Y.; Munk, B.H.; Muller, J.G.; Gogbill, A.; Burrows, C.J.; Schlegel, H.B. Mechanistic aspects of the formation of guanidinohydantoin from spiroiminodihydantoin under acidic conditions. Chem. Res. Toxicol. 2009, 22, 526-535.

10. Luo, W.; Muller, J.G.; Rachlin, E.M.; Burrows, C.J. Characterization of hydantoin products from one-electron oxidation of 8-oxo-7,8-dihydroguanosine in a nucleoside model. Chem. Res. Toxicol. 2001, 14, 927-938.

11. Suzuki, M.; Kino, K.; Morikawa, M.; Kobayashi, T.; Komori, R.; Miyazawa, H. Calculation of the stabilization energies of oxidatively damaged guanine base pairs with guanine. Molecules 2012, 17, 6705-6715.

12. Kornyushyna, O.; Berges, A.M.; Muller, J.G.; Burrows, C.J. In vitro nucleotide misinsertion opposite the oxidized guanosine lesions spiroiminodihydantoin and guanidinohydantoin and DNA synthesis past the lesions using Escherichia coli DNA polymerase I (Klenow fragment). Biochemistry 2002, 41, 15304-15314.

13. Frisch, M.J.; Trucks, G.W.; Schlegel, H.B.; Scuseria, G.E.; Robb, M.A.; Cheeseman, J.R.; Montgomery, J.A.; Vreven, T., Jr.; Kudin, K.N.; Burant, J.C.; et al. Gaussian 03, Revision C.02; Gaussian, Inc.: Wallingford, CT, USA, 2004.

14. Yan, S.F.; Wu, M.; Geacintov, N.E.; Broyde S. Altering DNA polymerase incorporation fidelity by distorting the dNTP binding pocket with a bulky carcinogen-damaged template. Biochemistry 2004, 43, 7750-7765. 